\title{
Enhanced settling of mature fine tailings (MFT) by paramagnetic nanofluids based on nanoiron
}

\author{
María Florencia Goddio ${ }^{1}$, Gerardo Daniel López ${ }^{2}$
}

\author{
${ }^{1}$ Nanotek S.A., Güemes 3878, Depto. 4, Santa Fe, Argentina \\ e-mail: flor_goddio@hotmail.com \\ ${ }^{2}$ Facultad Regional Santa Fe, Universidad Tecnológica Nacional, Lavaise 610, Santa Fe, Argentina \\ e-mail: gerardo@santafe-conicet.gob.ar
}

\begin{abstract}
The extraction of bitumen from sand by utilizing hot water processes results in the production of a slurry waste which is stored in so called "tailings ponds". Within these ponds, while fast settling sand particles segregate from the slurry in relatively short time, the fines fraction accumulates in the center of the pond and then settles, becoming mature fine tailings (MFT). Most of the water content of the pond is recycled back, however around $86 \%$ of the volume of MFT consist of water and it cannot be recycled. It takes a few years after placement for MFT to settle to around 35\% solids. By 2008 there were about 750 million cubic meters of MFT within the tailing ponds. Assuming the tailing management remains the same, the amount of fluid tailings is expected to reach two billion cubic meters by 2034. In 2009 it was estimated that there were around 130 square kilometers of tailings ponds in the oil sand region at Canada. Thus, one of the most important environmental challenges regarding oil sands mining is developing a process to separate water from the fine tailings within a reasonable time frame, in order to allow for the reclamation of the site. Bearing in mind these problems we initiated a preliminary applied research program in order to prove the concept of speeding up sedimentation of MFT by means of nanoparticles, and more specifically by using paramagnetic nanofluids manufactured with these nanoparticles. This preliminary series of tests proved that the concept of enhancing settling of MFT by means of paramagnetic nanofluids is feasible. Clarification of samples treated with magnetic nanoparticles achieved a $50 \%$ value as compared to only a $10 \%$ clarification in the same lapse for untreated samples, while dosage of conventional flocculants resulted in erratic behavior.
\end{abstract}

Keywords: nanofluids, paramagnetic, mature fine tailings

\section{INTRODUCTION}

The extraction of bitumen from sand by utilizing hot water processes results in the production of a slurry waste which is stored in so called "tailings ponds". Within these ponds, while fast settling sand particles segregate from the slurry in relatively short time, the fines fraction accumulates in the center of the pond and then settles, becoming mature fine tailings (MFT). CHALATURNYK et al. [1] state that most of the water content of the pond is recycled back, however around $86 \%$ of the volume of MFT consist of water. According to BEIER et al. [2], it takes a few years after placement for MFT to settle to around 35\% solids. By 2008 there were about 750 million cubic meters of MFT within the tailing ponds. HOULIHAN and HANEEF [3] mention that assuming that the tailing management remains the same, the amount of fluid tailings is expected to reach two billion cubic meters by 2034. In 2009 it was estimated that there were around 130 square kilometers of tailings ponds in the oil sand region at Canada. Thus, one of the most important environmental challenges regarding oil sands mining is developing a process to separate water from the fine tailings within a reasonable time frame, in order to allow for the reclamation of the site.

To illustrate the magnitude and economical importance of the problem, we refer to information published in the web. For example, the Canadian Association of Petroleum Producers estimated that by 2013, oil sands operators have been investing more than $\$ 1$ billion in tailings-reduction technology [4]. Suncor Energy, a company developing oil sands, mentions in its report on sustainability dated 2013 [5], that as of 2012 , they have spent more than $\$ 1.3$ billion to research, develop and implement its TRO ${ }^{\text {TM }}$ process, that allegedly will allow them to dry their mine tailings into a material solid enough to be reclaimed in a fraction of the time that earlier technologies require. This should, in turn, greatly accelerate their overall mine reclamation efforts because with the new drying process in place, they expect to reduce the time it takes from 
initial land disturbance to having a reclaimable surface to about 10 years, a third of what is now the industry standard.

Nevertheless, these technological promises seem to be unrealized to date. To put it in ANTWEILER's words [6]: "Tailings from bitumen mining are a mixture of water, sand, and fine clay, and also contain residual bitumen. These tailings are drained into settling ponds where sedimentation separates the ingredients. Water rises to the top, while heavier materials such as metals and minerals settle at the bottom of the pond. The difficulty arises with a middle layer of 'mature fine tailings' (MFT), which take a very long time to settle, even decades. This makes tailings ponds inefficient for treating tailings. Speeding up the process has become a new challenge for oil companies, which are under a mandate from Alberta's provincial government to meet capture targets for fine tailings. Introduced in 2009 as Directive 74 by the Alberta Energy Regulator (AER), companies are required to capture more than $50 \%$ of fines (particles of 44 micrometers or less) since 2013. Companies are scrambling to meet this target. In 2013, oil-sands mines owned by Shell, Suncor, and Syncrude failed to meet targets."

Bearing in mind the problems described above, we initiated a preliminary applied research program in order to prove the concept of speeding up sedimentation of MFT by means of nanoparticles, and more specifically by using paramagnetic nanofluids manufactured with these nanoparticles. Though the procedure has not been previously applied to MFT, there is some recent bibliographical background on using functional iron based nanoparticles for demulsification purposes due to their response to external magnetic fields and easy separation from multiphase systems under an external magnetic field [7-9].

\section{MATERIALS AND METHODS}

\subsection{Conceptual framework}

The key factor for dealing with MFT is to break the stable multiphase emulsion. It has been shown that the nano sized clay particles form fractal flocs that eventually interact to give a thixotropic gel [10]. Chemical demulsifiers are amphiphilic compounds having both hydrophilic and hydrophobic properties, which allow them to adsorb and interact at the oil/water interface that surrounds inorganic particles of sand and the like. To break the stable oil/water interface around emulsified fine solids, chemical demulsifiers are required to be more surface-active than the mechanisms acting as emulsion stabilizers. Magnetic Nano Particles (MNPs) particles are of great interest for this function because of their response to an external magnetic field for quick and easy isolation from the complex multiphase systems by magnetic separation. The interfacial activity of MNPs on the surface of micronic and submicronic particles have been found to allow them to be effectively attached to otherwise stable emulsified water droplets in diluted bitumen emulsions.

By working with hydrophobic magnetic nanoparticles, it should be possible to control the surface activity of the particles in mixed media. By tuning the wettability of the suspended particles, influence can be exercised on properties at the oil-water interface. This can be done by dispersion of MNPs into the stable emulsion, being the surface ligands number of the MNPs an important factor to affect the process, which is mainly governed by the increase of the interfacial viscoelasticity resulting from the attachment of MNPs.

The interfacial activity and high hydrophilic nature of Polymer/FenOx magnetic nanoparticles (which we can denominate by the generic formula Fe3O4@) will allow them to be effectively attached to stable emulsified sand-water droplets in oil - water emulsion, and tagged water can be readily removed by an external magnetic field, which enhances the coalescence of magnetically tagged water droplets in an emulsion. The magnetic property of Fe3O4@ should allow this kind of MNPs to be readily recycled by magnetic separation and solvent washing. Polymer/FenOx magnetic nanoparticles should be designed so as to retain their interfacial activity when recycled. The conceptual mechanism is a combination of the following stages:

1. Fe3O4@ enter to the oil water interface surrounding inorganic solids micro particles (MFT) and breaks up the interfacial film formed by surface-active components in this interface due to the more surface active and hydrophilic nature of Polymer/FenOx magnetic nanoparticles

2. Fe3O4@ particles increase the rate of partition coefficient and increase the adsorption of demulsifier molecules at the oil/water interface

3. Fe3O4@ particles aggregate water droplets through bridging flocculation leading to their coalescence. 
This mechanism will obviously be influenced by parameters such as dosage, wettability (or water contact angle) of the nanoparticles and $\mathrm{pH}$, at least. Demulsification Efficiency (DE) should increase with increasing Fe3O4@ dosage. High wettability (i.e. water contact angle of $\geq 90^{\circ}$ ) will be desirable. Acid to neutral conditions should have little influence, alkaline $\mathrm{pH}(\geq 9)$ should have adverse effects on DE. Probably a multistep operation will exhibit a higher DE than a single-step demulsification when the same amounts of Fe3O4@ are used. Figure one is a graphical abstract of the described conceptual mechanism [11].

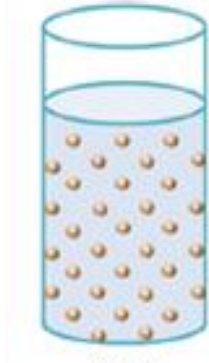

O/W Nanoemulsion

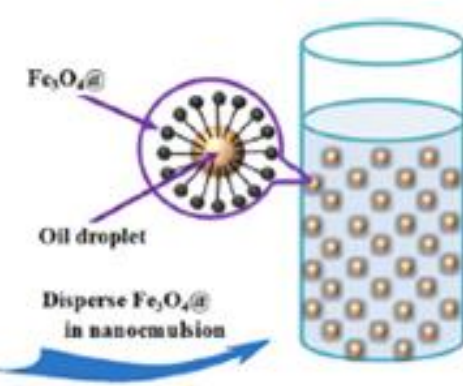

in nathernebion

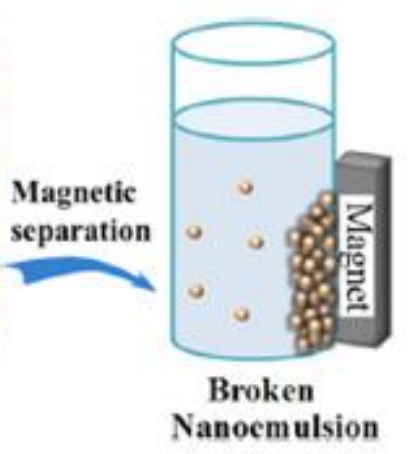

Figure 1: Demulsification mechanism by means of magnetic nanoparticles.

\subsection{Methodology}

The short R\&D program mentioned at the introduction comprised three main steps

Phase one: nanomaterials development

The main purpose of this stage was to manipulate hydrophilic / hydrophobic characteristics of the demulsifiers, without impairing paramagnetic behavior. Additional desired properties included compatibility with aqueous media (tailing ponds are, basically, deposits of contaminated water) and minimal environmental impact (which was pursued by using biodegradable organic compounds for functionalization purposes). The main problem was to keep reasonable magnetic properties after covering the nanoparticles with hydrophilic organic envelopes.

Phase two: previous screening of formulations

This was done at lab scale. The main objective of this stage was to discard formulations according to settling efficacy of each one. This phase of R\&D was not concerned with economics, so that great percent dosages were used to obtain clear and quick differential responses. Figure two shows initial experimental array. Two sets of conditions were evaluated: magnetic assisted settling (to the left on Figure 2) and gravity settling (to the right on Figure 2). The test tubes of each group have the same compositions, so that the only difference between groups to be assessed would be the effect of the magnetic field on the settling process. 


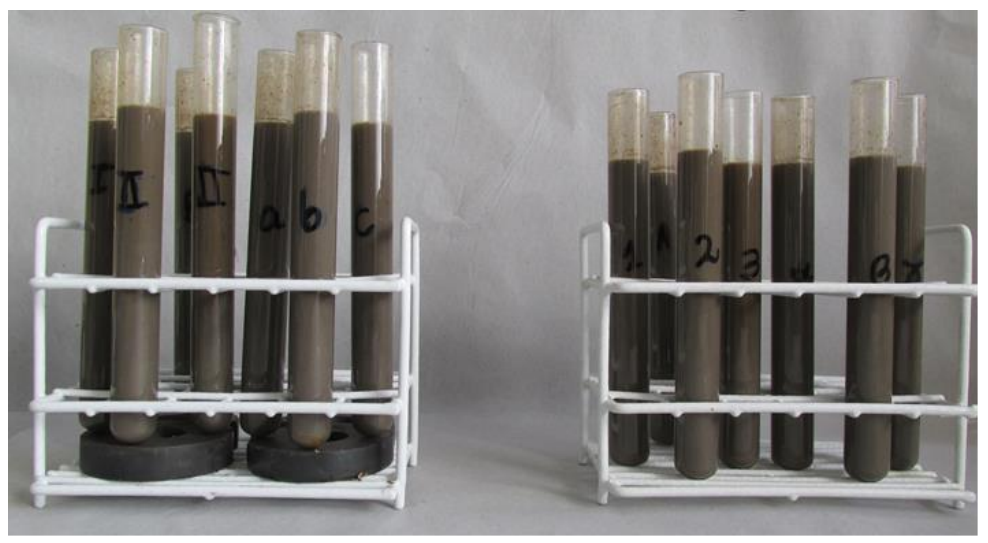

Figure 2: Experimental array for screening stage - day one.

Phase three: adjustment of dosage

This was done at lab scale. Formulations that showed the best responses at stage two were controlled against commercial flocculants based on conventional aluminum sulphate. Experimental array was similar to that of phase two, as shown by Figure three.

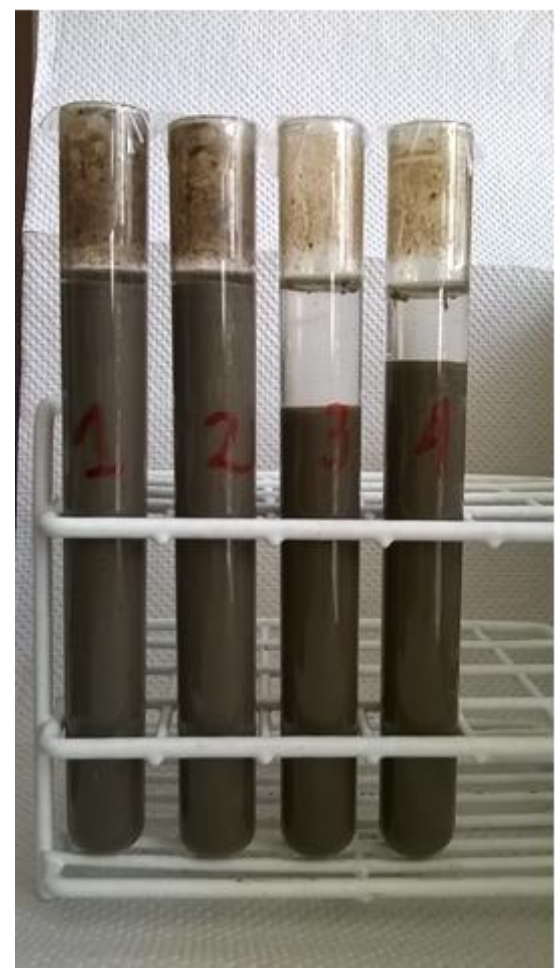

Figure 3: Experimental array for third stage - day n.

\subsection{Materials}

For the synthesis of magnetic nanoparticles controlled co-precipitation techniques were used. The chemical reaction utilized in these procedures involved alkinization of ferric and ferrous species. One major obstacle when employing such direct techniques is the aggregation of colloidal particles towards lower surface energy. Steric stabilization of suspended nanoparticles (also termed stabilization) provides resolution of this problem.

Thus, magnetic nanoparticle synthesis and stabilization was achieved from a stock solution containing 1:2 molar ratio ferrous:ferric species (ferrous chloride and ferric chloride) which was slowly poured (dropwise) into alkali source, composed of sodium hydroxide, under vigorous stirring and nitrogen sparging. 
Magnetic crystals (magnetite and / or maghemite) formed and precipitated.

In the preparation and storage of ferrofluids, the stability is of utmost importance. Organic compounds are often employed to passivate the surface of the iron oxide NPs during or after the preparing procedure to avoid agglomeration. The main reason for magnetic iron oxide nanoparticles agglomeration is that they have hydrophobic surfaces with a large surface area to volume ratio so that if in the absence of any proper surface coating, the hydrophobic interactions between the NPs will cause them to form large clusters, resulting in increased particle size. The structure of organic compounds functionalized magnetic iron oxide nanoparticles must be such as to preserve both, the magnetic properties of iron oxides and the other properties of organic molecules, such as hydrophilic and hydrophobic characteristics.

Among the different matrixes that can be used to embed the nanoparticles, polymers are of particular interest because of their wide range of properties. Bearing this in mind, four types of natural organic stabilizers were used to prepare the ferrofluids formulations to be assessed: dextran, starch, gelatin and chitosan.

\subsection{Samples}

The tests were carried on with a sample of real MFT, as described below. Material was received from Canada and included an MSDS by ALBERTA INNOVATES Technology Futures, which characterized the contents as follows:

Product: Mature fine tails

Use: by product of the extraction of bitumen from oil sand

Producers: Syncrude Canada Ltd. / Shell Canada Ltd. / Canadian Natural Resources Ltd

Composition: Thickened suspension of fine particles of clay and silt size minerals in water, formed by setting of process tailings from the separation of bitumen from oil sand.

Ingredients:

Naphta (CAS \# 64742-48-9)

Clay (N/A)

Water (CAS \# 7732-18-5)

$$
\begin{aligned}
& 1-2 \text { Wt. } \% \\
& <0.1 \text { Wt. } \%
\end{aligned}
$$

$30-60 \%$

balance

\section{RESULTS}

The different stages of work resulted as follows:

Phase one: Based on Nanotek's expertise and current range of own manufactured nanomagnetic particles as a starting point, several formulations, as described in section 2.3, were prepared to be assessed at phase 2.

Phase two: Figure four shows behavior of different formulations after six months of magnetically assisted sedimentation. 


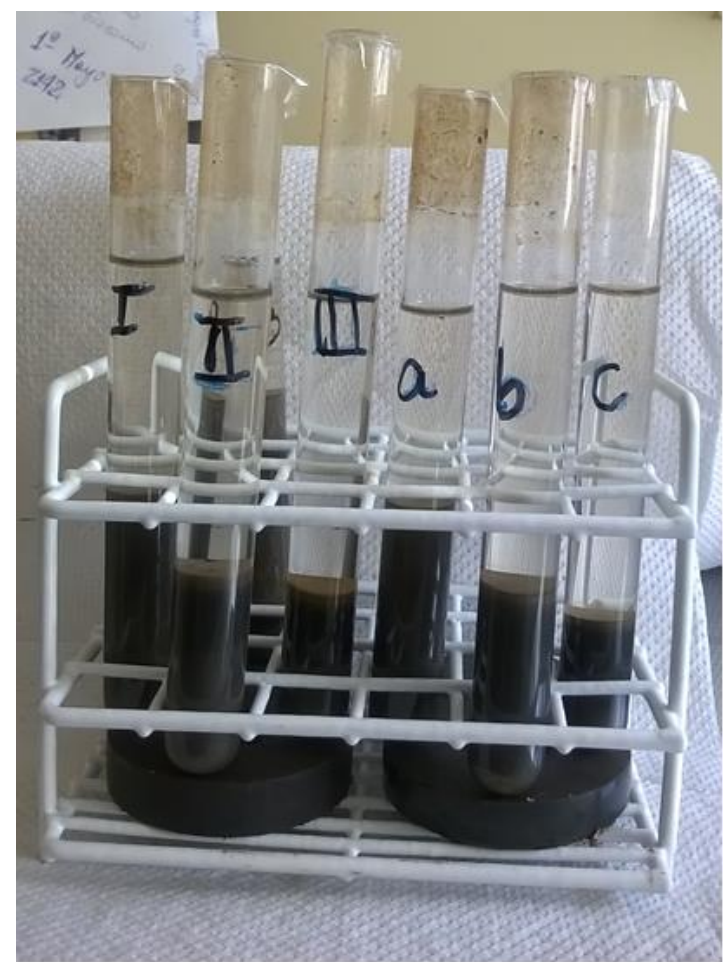

Figure 4: Demulsification after six months (magnetically assisted).

Figure five represents graphically the results obtained for the first two weeks. It can be seen that all four samples dosed with nanoparticles (upper lines) tend to converge around a clarification over 50\%, while duplicate untreated samples (lower lines) achieve barely a 10\% clarification for the same time lapse. Both types of samples, dosed and not dosed, exhibit asymptotic behavior after a short initial period of time.

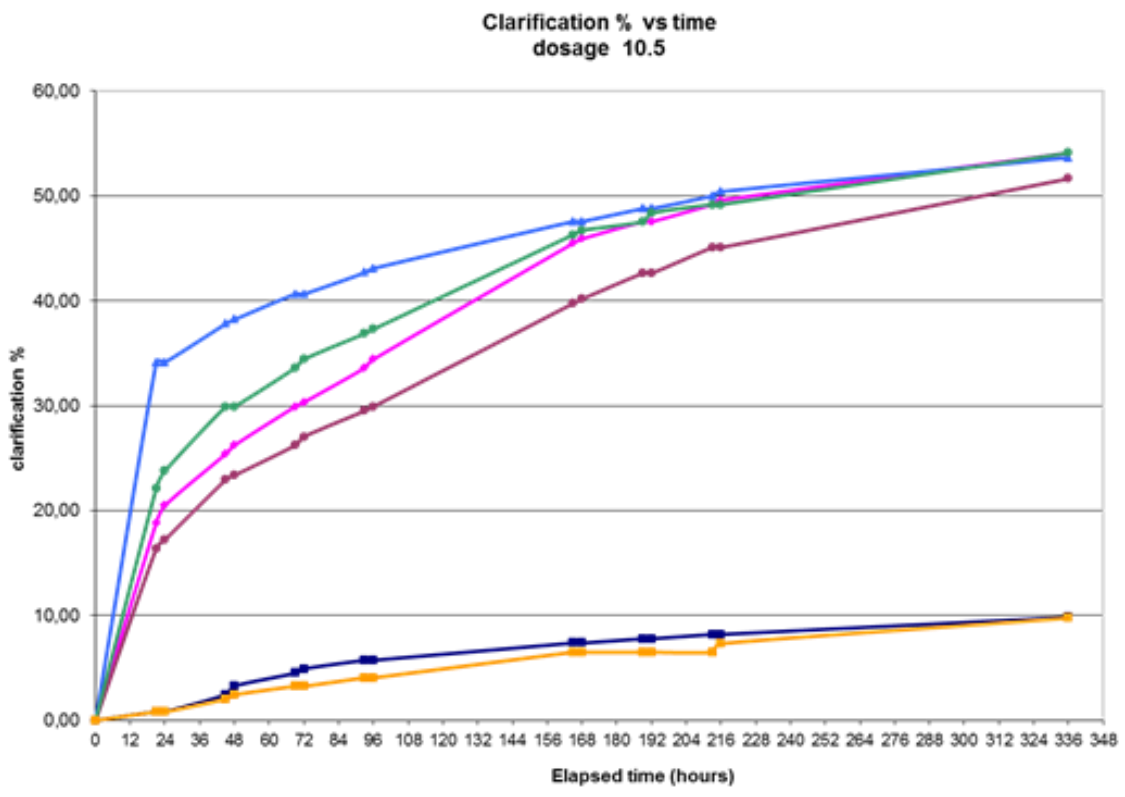

Figure 5: Clarification versus time - screening of formulations.

Phase three: once dosage was adjusted based on results from phase two, selected different formulations were assessed. Their comparative behavior against conventional flocculants is illustrated by 
Figure six. The clarification obtained after eighteen days for these lower dosages can be seen in Figure seven. Duplicate untreated samples (lower lines) achieve slightly less than $10 \%$ clarification for this time lapse. Three of the four samples dosed with nanoparticles (upper lines) tend to converge around a clarification between 25 and $30 \%$, while the sample dosed with conventional flocculant (upper interrupted line) showed an erratic behavior as illustrated by Figure six, which inhibited a further comparison of clarification after the first week. Lowering the dosage of nanoparticles allowed distinction of performance between formulations by amplification of distances between them, but nevertheless the asymptotic behavior after a short initial period of time seems to be present again.

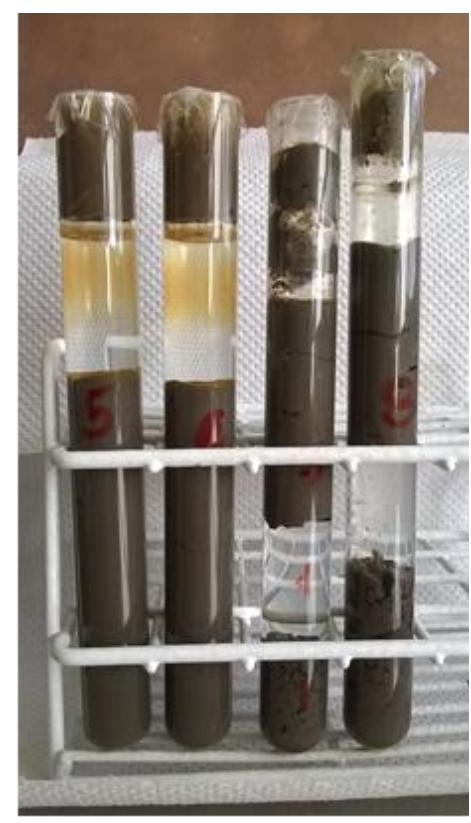

Figure 6: Behavior of selected MNPs (left) versus conventional flocculant (right)

\section{DISCUSSION}

From the results depicted in the previous section it was evident that conventional flocculants (to the right in the Figure 6) were not eligible, because instead of promoting a clear separation between phases, they generated a stratification of the MFT sample, with an upper floating phase with high solids content, a liquid phase of clarified water at the middle, and another agglomeration of material rich in solids at the bottom. This behavior will prevent the design of a sensible treatment at field scale.

Figure seven represents graphically results obtained after 18 days. The two samples for which data is only shown up to the first 8 days (upper interrupted lines) are those treated with conventional flocculants, because the clarified phase (which was stratified at the middle of the test tubes as mentioned before) continued showing an erratic behavior instead of increasing with time, and thus this data was considered not relevant.

By comparing Figures 7 and 5 it can be easily inferred that different formulations (i.e. similar nanoparticles with different organic stabilizers) have little impact on long range performance, as shown by the asymptotic behavior. Conversely, dosage is a very important parameter, because when lesser amounts of ferrofluids are added to the samples, the corresponding efficacy measured as percentage of clarified zone versus sedimentation zone seems is diminished, at least in relatively short lapses of time (less than three weeks). However, as seen in Figure four, for longer periods of time magnetically assisted settling reaches substantially higher values, in the range of 60 to $70 \%$. This leads to the conclusion that a competitive solution at field scales should balance long term sedimentation at low dosages against short term clarification with associated costs of higher dosages. 


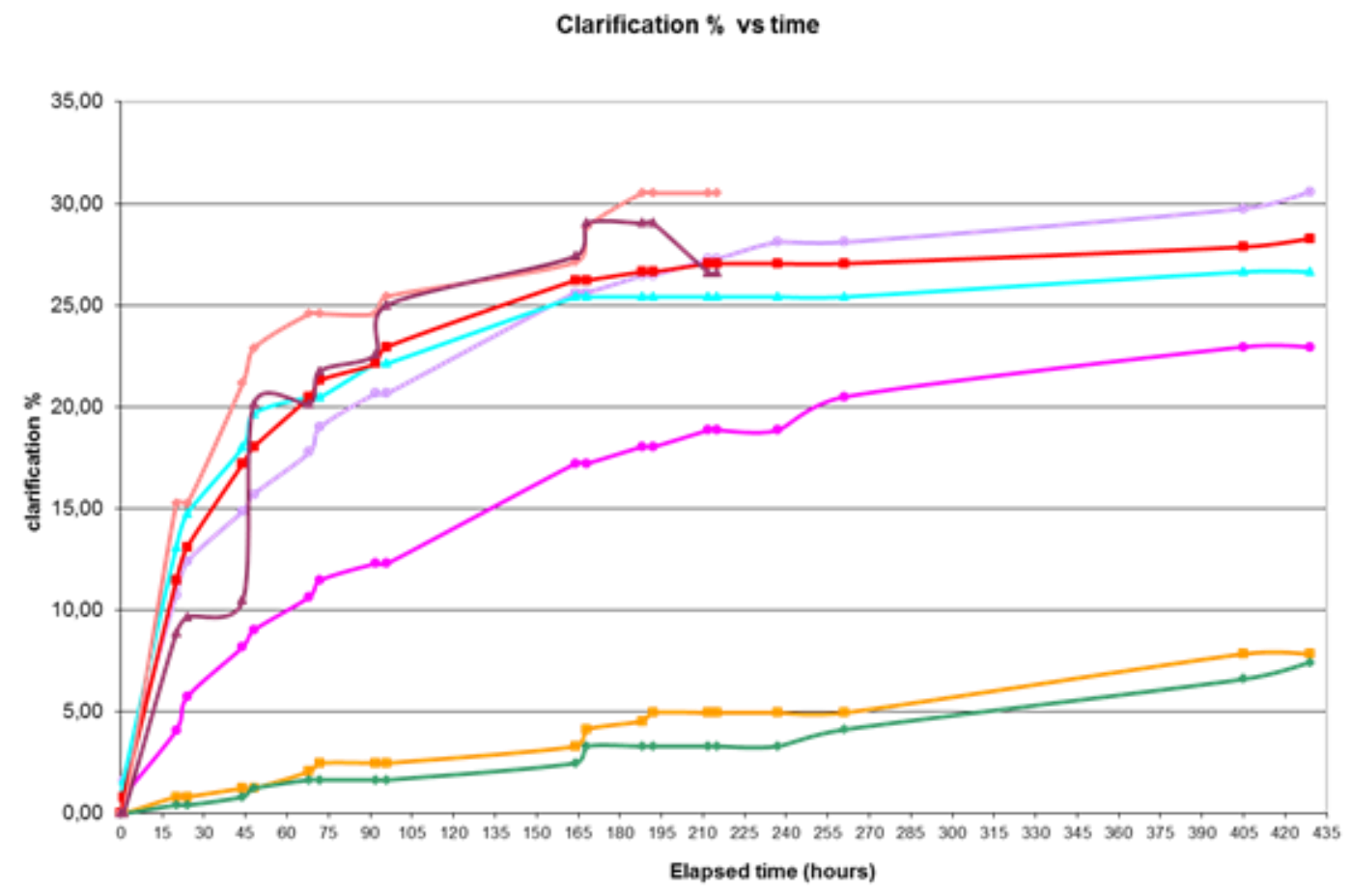

Figure 7: Clarification versus time - adjustment of dosage

\section{CONCLUSIONS}

These preliminary series of tests prove that the concept of enhancing settling of MFT by means of paramagnetic nanofluids is feasible. From this onwards a series of steps should be taken in order to reach the market with a competitive formulation based on functionalized nanoiron. Briefly, these stages would include, for a first immediate phase:

1. Optimization of dosage at lab-bench scale, taking into account asymptotic behavior in the log range for the more successful formulations.

2. Assessment of various alternatives amenable to treatment at field scale, including direct mixing into the slurry of existing tailings within a pond, mixing prior to flowing into the tailings pond, simple mixing and gravity settling versus mixing combined with external magnetic fields (either fixed as in the reported lab tests, or variable at different intensities and geometries) to fasten the reaction and / or achieve higher efficiencies, and other alternatives.

3. Scaling up of the production process for the functionalized nanoparticles. The current plant for production of magnetic nanoparticles at Nanotek is based on a different synthesis pathway from those tested with MFT, so that a new process has to be designed from conceptual engineering to basic engineering, detailed blueprints and construction of a production plant at commercial level.

4. Bench scale demonstration of the treatment defined from previous screening (step 2)

\section{BIBLIOGRAPHY}

[1] CHALATURNYK,, R.J., SCOTT, J. D.., OZUM, B. "Management of oil sands tailings", Petroleum Science and Technology, v. 20, pp. 1025-1046, 2002.

[2] BEIER, N., ALOSTAZ, M., SEGO, D. "Natural dewatering strategies for oil sands fine tailings"; In Proceedings Thirteenth International Conference on Tailings and Mine Waste, pp. 845-858, Banff, Alberta, Canada, November 2009

[3] HOULIHAN, R., HANEEF, M. "Oil Sands Tailings: Regulatory Perspective”, In Proceedings First International Oil Sands Tailing Conference, pp. 250-264, Edmonton, Alberta, Canada, December 2008 
[4] CANADIAN ASSOCIATION OF PETROLEUM PRODUCERS, OIL SANDS TODAY, http://www.homerdixon.com/wp-content/uploads/2013/04/tar-sands-70-sq-mi.pdf, Accessed in November 2016.

[5] Suncor Energy, REPORT ON SUSTAINABILITY 2013, http://sustainability.suncor.com/2013/en/environment/tailings.aspx , Accessed in November 2016.

[6] Werner Antweiler, WERNER'S BLOG — OPINION, ANALYSIS, COMMENTARY, http://wernerantweiler.ca/blog.php?item=2014-09-02, Accessed in November 2016.

[7] PENG, J. X., LIU, Q. X., XU, Z. H., et al., "Synthesis of Interfacially Active and Magnetically Responsive Nanoparticles for Multiphase Separation Applications", J. Adv. Funct. Mater., v. 22, pp. 1732-1740, 2012.

[8] LEMOS, B. R. S., TEIXEIRA, A. P. C., ARDISSON, J. D., et al., "Magnetic amphiphilic composites applied for the treatment of biodiesel wastewaters", Appl. Sci., v. 2, pp- 513-524, 2012.

[9] CALCAGNILE, P., FRAGOULI, D., BAYER, I. S., et al., "Magnetically driven floating foams for the removal of oil contaminants from water", A. ACS Nano, v. 6, pp. 5413-5419, 2012.

[10] KOTYLAR, L. S., SPARKS, B. D., SCHUTFE, R. "Effect of salt on the flocculation behavior of nano particles in oil sands fine tailings", Clays and Clay Minerals, v. 44, n. 1, pp. 121 131, 1996.

[11] LIANG, J., DU, N., SONG, S., et al., "Magnetic demulsification of diluted crude oil-in-water nanoemulsions using oleic acid-coated magnetite nanoparticles", Colloids and Surfaces A: Physicochem. Eng. Aspects, 466, pp. 197-202, 2015 